\title{
Mediterranean forest dynamics and forest bird distribution changes in the late 20th century
}

\author{
ASSU GIL-TENA*, LLUÍS BROTONS †† and SANTIAGO SAURA* \\ *Departament d'Enginyeria Agroforestal, Universitat de Lleida, ETSEA, Av. Alcalde Rovira Roure 191, 25198 Lleida, Spain, †Àrea \\ de Biodiversitat, Centre Tecnològic Forestal de Catalunya, C/Pujada del Seminari s/n, 25280 Solsona, Lleida, Spain, †̇nstitut Català \\ d'Ornitologia, Museu de Ciències Naturals, Zoologia, Passeig Picasso s/n, 08003 Barcelona, Spain
}

\begin{abstract}
Processes derived from global change such as land-use changes, climate warming or modifications in the perturbation regime may have opposite effects on forest extent and structure with still unknown consequences on forest biodiversity at large spatial scales. In the present study, we aimed at determining forest dynamics associated with global change processes (forest spread, maturation and fire) that have driven the variation in forest bird distributions in Mediterranean forest ecosystems in recent years. The study was located in Catalonia (NE Spain) and used changes in richness of specialist and generalist forest bird species in the last 20 years of the 20th century as indicators of forest biodiversity change. Forest bird distribution changes showed strong spatial patterns and appeared to be related to population processes occurring beyond sampling units $(10 \mathrm{~km} \times 10 \mathrm{~km}$ squares). Forest maturation appeared as the most important driver of such changes because most of the studied species have a non-Mediterranean origin and are associated with more mature forests. To a lower degree, forest spread also contributed to forest bird distribution changes whereas the impact of forest fires was not associated to a decrease in the richness of either group of forest species. Given the relatively coarse scale at which our study was conducted, caution should be taken when extrapolating our results to the possible future impacts of climate change on fire regime and forest bird distribution. Our results indicate that large-scale forest maturation and spread due mainly to land abandonment in Catalonia has overridden the potentially negative effects of fires on forest bird distributions and are currently driving changes in forest biodiversity patterns across the region.

Keywords: dispersal, forest maturation, forest spread, generalist and specialist forest bird species, hierarchical modelling, land abandonment, mixed models, regional processes, spatial autocorrelation, wildfires
\end{abstract}

Received 9 May 2008 and accepted 28 July 2008

\section{Introduction}

Humans are increasingly having profound effects on the environment at a global scale. Current global environmental change is commonly viewed as a combination of processes acting at different spatial and temporal scales on the current state of ecological communities (IGBP, 2001). Interactions between climate change and other components of global change such as land-use changes are expected to have strong impacts in the

Correspondence: Lluís Brotons, Àrea de Biodiversitat, Centre Tecnològic Forestal de Catalunya, C/Pujada del Seminari s/n, 25280 Solsona, Lleida, Spain, tel. + 349734817 52, fax + 3497348 13 92, e-mail: lluis.brotons@ctfc.cat structure of communities (Sala et al., 2000; Thomas et al., 2004). Because of their high exposure to human activities (Blondel, 2006) and sensitivity to climatic conditions (Peñuelas et al., 2002), Mediterranean ecosystems appear to be especially susceptible to the impacts of global change (Lavorel et al., 1998). This is because many large-scale factors such as climate and land-use changes or modifications in the perturbation regime are expected to be simultaneously impacting these regions with largely unknown overall effects on current biodiversity patterns (Sala et al., 2000).

In most of the Mediterranean region, rural land abandonment has occurred during the last century leading to the naturalization and vegetation closure of many areas and favouring the spread of forest (e.g. 
Debussche et al., 1999; Poyatos et al., 2003; RouraPascual et al., 2005). The reduction in forestry activities due to the low profitability of traditional forest products, the introduction of new fuel sources and the subsequent abandonment of firewood and charcoal production have boosted the trend from open woodlands to dense forests with increasing forest age (maturation) and biomass (Poyatos et al., 2003; RouraPascual et al., 2005). Climatic and atmospheric changes occurred during the second half of the past century such as increasing temperatures and $\mathrm{CO}_{2}$ concentrations may also have contributed to the growth and maturation of forest ecosystems especially in areas where water is not a limiting factor (Boisvenue \& Running, 2006).

On the other hand, fire is a common disturbance in Mediterranean forest landscapes counteracting in many areas the effects of forest spread associated to land abandonment (Mouillot et al., 2005). Fire regime is the result of a complex combination of factors including fuel accumulation and climatic conditions, and there is evidence that forest fire occurrence and extent have increased during the last years of the 20th century in large regions of the Mediterranean (Mouillot \& Field, 2005), particularly in the form of large wildfires. Fuel accumulation and landscape homogeneity derived from rural land abandonment (Lloret et al., 2002; Vega-García \& Chuvieco, 2006) together with a higher number of ignitions derived from land-use changes and an increased number of extreme dry and hot summer events associated to climatic change (Piñol et al., 1998) have been argued to be the main factors behind recent changes in fire regime in the region.

Processes related to global change such as land-use changes and fire may lead to opposite trends on forest structure and extent, and their relative effects on biodiversity patterns are likely to depend on the importance of each process at the landscape scale and the interactions established between them (Moreira \& Russo, 2007). A large number of forest bird species appears to benefit from forest spread at local (Preiss et al., 1997; Moreira et al., 2001; Suárez-Seoane et al., 2002; Laiolo, 2005; Sirami et al., 2007b) and regional scales (Reif et al., 2007). Forest maturation related to land abandonment has also been suggested as beneficial to forest birds (Reif et al., 2007) but has not been directly tested.

Although, in general, the population of many common forest birds appears to be declining in some parts of Europe (Fuller et al., 2005), there is a degree of variation across the continent with increasing populations of some others which may be linked with land abandonment and the subsequent natural afforestation (Gregory et al., 2007). As suggested by Preiss et al. (1997) at the landscape scale, an increased and less fragmented forest cover could allow a regional colonization by some mid-European forest birds that the absence of large forest tracts has kept away from the Mediterranean lowlands.

To our knowledge, the weight of different ecological processes in driving the changes in the distribution area of forest bird species in the Mediterranean region is still unknown, and particularly, which of these processes are related with forest dynamics. In this context, the Catalan Breeding Bird Atlases (CBBA) offer a new regional perspective of temporal changes in the species distribution in Catalonia (NE of Spain) in a period 20 years apart, being changes in bird distribution often strongly related with species' population trends (see Donald \& Fuller, 1998). In addition, the development of forest databases such as the Spanish National Forest Inventory and other land cover maps can gather information about the dynamics of forest ecosystems in this region. Thus, our study is, to our knowledge, the first to quantify the relative effect of contradicting processes of different components of global change on the distribution of forest bird diversity in a Mediterranean context.

In this study, we aimed at determining the type of forest dynamics associated mainly with land abandonment that may have potentially driven the variation in forest bird distributions in Mediterranean forest ecosystems in recent years. We analysed two indicators of forest bird distribution changes in the study area: the variation in species richness during the period between atlases for specialist and generalist birds. We considered three different types of forest descriptors associated to changes in forest characteristics related with land abandonment as possible drivers of forest bird distribution changes: increases in forest area (estimated from landuse maps), forest maturation (estimated from largescale forest inventory data) and the area affected by forest fires (estimated from official forest fire perimeters). We specifically wanted to determine the following: (i) At which scale have changes in forest bird distributions occurred? We expect here that in the case that local processes are the main drivers of change, changes in bird distributions will have a weak spatial structure and show low spatial autocorrelation patterns. If, on the contrary, bird distribution changes are caused by landscape or regional processes, they will have a strong geographical response showing strong spatial autocorrelation patterns (Diniz-Filho et al., 2003; Gimona \& Brewer, 2006). (ii) Which forest descriptors are the best predictors of forest bird distribution change and at which spatial scale? We anticipate that if forest dynamics, mostly derived from land abandonment, are the main drivers of forest bird distribution change, both forest spread and increases in forest growth stocks (maturation) will be the main predictors (see Estrada 
et al., 2004). On the other hand, if wildfires have a predominant role, we expect a local effect of fire impact on forest bird distribution change (Brotons et al., 2004).

\section{Material and methods}

\section{Study area}

Catalonia $\left(32107 \mathrm{~km}^{2}\right)$ is a region located in northeast Spain (Fig. 1) comprising a range of habitat types from mountainous areas in the Pyrenees and inland chains (with an altitude up to $3143 \mathrm{~m}$ ) to a long coastline along the Mediterranean Sea. The climate is mainly Mediterranean temperate, with maritime influence in the coast and a cold influence in the Pyrenees. Prominent land abandonment in the last decades has favoured shrub encroachment and the natural colonization of forest, mostly in less productive and less accessible areas (e.g. Poyatos et al., 2003).

According to the Land Cover Map of Catalonia, about of $61 \%$ of Catalonia is covered by forests and other shrubby lands (Terradas et al., 2004). Forests are characterized by a wide diversity and about a hundred different tree species exist in this region, although $90 \%$ of the total number of trees is from the 14 most common species (Gracia et al., 2004). Despite the fact that forest fires had burned approximately 240000 ha between

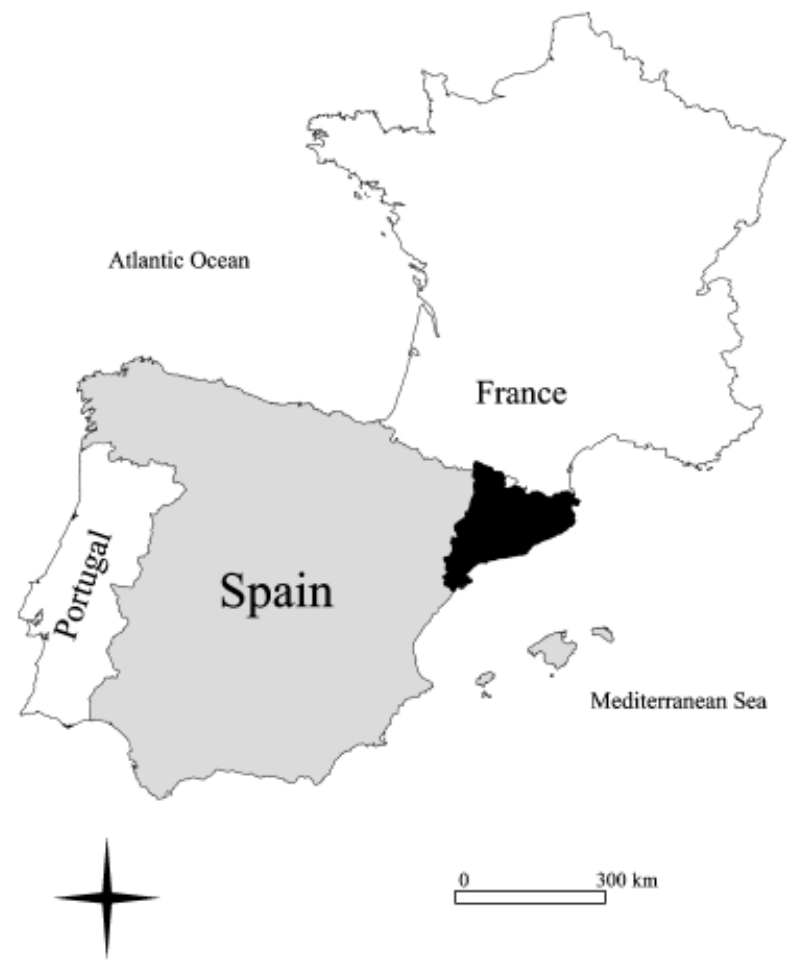

Fig. 1 Geographic location of the study area (Catalonia), shown in black colour.
1975 and 1998 (about 12\% of the total area covered by forest and other shrubby lands; Díaz-Delgado et al., 2004), Catalan forests have still increased their absolute cover by about $1.54 \%$ between 1987 and 1997 according to the Land-use Map of Catalonia (Viñas \& Baulies, 1995). In line with these data, Catalan forests have significantly aged and accumulated biomass during the last years of the 20th century. Comparing data from the Second and Third National Forest Inventory between 1989 and 2001 in Catalonia, there was a significant increment of both forest basal area $\left(\mathrm{m}^{2} \mathrm{ha}^{-1}\right)$ and top height $(\mathrm{m})$ of $27 \%$ and $8 \%$, respectively.

\section{Forest bird changes}

To assess the factors behind variations in forest bird distribution, we used species occurrence data derived from the CBBA (Estrada et al., 2004). The CBBA consisted on large-scale surveys covering the whole extent of Catalonia in two different periods: 1975-1983 (Atlas 1) and 1999-2002 (Atlas 2). A total of $38510 \mathrm{~km} \times 10 \mathrm{~km}$ UTM squares were surveyed during the atlas field work in each of the different time periods. The aim of the survey was to detect the highest number of breeding species in each sample square. To do this, the observers were asked to gather, from March to July inclusive, breeding evidences of bird species occurring in all habitats within their square, including the scarcest ones. For a particular species, variations in distribution at a regional scale can be estimated by means of an analysis of the variations occurred in every $10 \mathrm{~km} \times 10 \mathrm{~km}$ UTM squares between atlases (Donald \& Fuller, 1998).

To analyse potential differences between ecological groups, we considered the variation in species richness between atlases separately for specialist and generalist forest bird species. We identified forest specialists and generalists by differences in the species forest and agricultural habitat selectivity indices derived from the bird atlas data (Estrada et al., 2004). Forest specialists were characterized by higher selectivity of forested landscapes and avoidance of agricultural dominated landscapes, whereas generalist species, despite showing positive selection of forested landscapes, did not clearly avoid agricultural landscapes (Appendix Table A1). The analysed species did not include: (i) the most common species ( $>90 \%$ of total squares in Atlas 2) or very scarce ( $<10 \%$ of total squares in Atlas 2$)$, (ii) with specific problems of detectability (e.g. Tetrao urogallus) or (iii) those species which tend to be irruptive or opportunistic (e.g. Carduelis spinus) (see Estrada et al., 2004). The total number of forest species complying with these criteria was 30 (16 specialists and 14 generalists). According to the CBBA (Estrada et al., 2004), most of the forest species considered here are expanding (12 
specialists and six generalists), while the rest remained stable but showing some local changes in distribution (two specialists and four generalists) or significantly contracted their range (two specialists and four generalists). From the species occurrence data for each Atlas period, we obtained the species richness for specialists and generalists for each $10 \mathrm{~km} \times 10 \mathrm{~km}$ UTM square.

Observed distribution changes may be related to temporal variation in sampling effort, which may mask real distribution changes (Donald \& Fuller, 1998). To differentiate between real changes in distribution and simple variations in the sampling effort between atlases, we applied regressions between the richness variables for each atlas and the variability in sampling effort available for each UTM square (log transformed; Estrada et al., 2004). We used the residuals of the former regressions to compute the variation in richness of forest bird species between atlases, which were the final dependent variables. Analyses of distributional variations were only conducted on the $80 \%$ of squares $(N=309)$ from which changes in sampling effort could be obtained [see also Estrada et al. (2004) and Carnicer et al. (2008) for more details on the procedure and its applications].

Species distributions and their dynamics often show a strong spatial component originated through a variety of ecological processes occurring at different spatial scales (Selmi \& Boulinier, 2001; Diniz-Filho et al., 2003). In our study, we explicitly included the spatial structure of specialist and generalist species pools in the modelling approach in order to account for spatial population processes related to dispersal in the recorded changes in the distribution of the species. In particular, population processes occurring in a given location may be related to changes occurring in the neighbourhood (Brotons et al., 2005, 2008; Gimona \& Brewer, 2006). We summarized, for a given $10 \mathrm{~km} \times 10 \mathrm{~km}$ UTM square, the information about specialist and generalist species richness variation on surrounding squares by means of contagion variables (Augustin et al., 1996). Avian contagion variables were computed by averaging specialist and generalist species richness variation on the UTM squares that had their centre located within a certain distance from the central UTM square, and excluding the values of that central UTM square from the average. For both types of dependent variables, four avian contagion variables were computed at different extents with a distance of 10, 20, 30 and $40 \mathrm{~km}$ from the edge of the central UTM square.

\section{Forest dynamics}

We considered forest spread and maturation, related to land abandonment and forest growth, and the area burnt by fires as the main components of the forest dynamics affecting the study area during the last 20 years. The absence of forest inventory and land-use map data matching the two atlases, forced us to quantify forest dynamics based on data from a somewhat narrower time window (1989-2001 for inventory data and 1987-1997 for land-use maps) than the time elapsed between the two bird atlases (from 1975-1983 to 19992002). We assumed that the estimation of the forest dynamics using the time window above is representative of the changes in forest extent and structure corresponding to the whole period between bird atlases since global change processes as land abandonment started a few decades ago in the study area (Terradas et al., 2004).

To evaluate forest spread, we considered the absolute variation of forest area obtained from the Land-use Map in Catalonia for 1987 and 1997 (Viñas \& Baulies, 1995). Forest fire data considered the amount of forest burnt area between Atlas 1 and Atlas 2 from fire perimeter government statistics data for 1980-2000 at the municipal level (Catalan Department of Housing and Environment, 2007).

To assess forest maturation we considered the absolute variation of basal area obtained from the permanent plots measured in the Second and Third Spanish National Forest Inventory (NFI 2 and 3, respectively; Ministerio de Medio Ambiente, 2006). In Catalonia, the field work for the NFI 2 was carried out from 1989 to 1991 whereas for the NFI 3 was from 2000 to 2001. The sampling density is about one NFI plot every $1 \mathrm{~km}^{2}$. The size of the NFI plots varies depending on the tree diameter at breast height, with a minimum plot radius of $5 \mathrm{~m}$ and a maximum of $25 \mathrm{~m}$. We used a subset of 7712 permanent plots measured in both inventories that were entirely within the UTM squares, considering for this study 5346 plots that had not been harvested or burnt by fires, thus estimating the variation of basal area due to maturation of the forest already existing in the NFI 2.

To determine whether the initial conditions of forest influence bird distribution change, we also computed the initial state of both basal and forest area. All the variables described above were computed at the $10 \mathrm{~km} \times 10 \mathrm{~km}$ UTM extent; besides, we also calculated four contagion variables for each descriptor in the same way as for the avian contagion variables.

\section{Analytical approach}

To determine at which scale forest bird distribution changes and forest dynamics operate, spatial patterns of bird distribution changes and forest dynamics were analysed by means of general linear modelling (Gimona \& Brewer, 2006). In this modelling approach, we considered that different processes may act at different 
spatial scales: local at the $10 \mathrm{~km} \times 10 \mathrm{~km}$ UTM square extent, landscape for the contagion variables at the extent of 10 and $20 \mathrm{~km}$ and regional for the contagion variables at extents equal or greater than $30 \mathrm{~km}$.

Forest bird species richness variation was tested by means of mixed models where specialization group (specialist vs. generalist), avian contagion variables and forest dynamics descriptors were introduced as fixed effects, and each value was corrected for the UTM square effect, being introduced in the model as a random factor to take into account the relationship between measurements within each UTM square. The MIXED procedure of SAS software (version 9.1, SAS Institute Inc., Cary, NC, USA) was used, and the effects of main fixed and random factors were studied ( $F$-test, $P<0.05)$. Least-square means were computed for the specialization group effect, and statistically separated using pairwise $t$-tests when a significant $(P<0.05) F$-test was observed.

To assess differences between specialization groups, we computed the interaction between the variable of specialization group and the significant forest dynamics' predictors. Interactions between the significant forest descriptors were also included to consider potential synergies between forest dynamics on forest bird distribution changes. In the case of significance of the linear component of variables describing forest dynamics, we also checked the effect of the quadratic term of each predictor to account for nonlinear relationships.

We developed three different models using a hierarchical modelling approach to progressively assess the role of these variables in different steps according to specific hypotheses (Herrando \& Brotons, 2002). Significant variables at each step were introduced in later steps and their contribution to the model evaluated by means of the increment of the determination coefficient $\left(R^{2}\right)$. To obtain the best set of explanatory variables, we employed the following selection process: first, the significant variable that accounted for the highest reduction in the Akaike's Information Criterion (AIC) respective to the null model was selected; then all the remaining variables were added one-by-one to the model and tested again for their significance and reduction in the change of AIC. The selection process was stopped when the variables to include were not significant or did not reduce AIC. We developed different statistical models according to different hypotheses:

MODEL 1. Forest bird distribution changes are associated not only to forest dynamics but also to bird spatial population processes both acting at different scales. In this model, we assessed the role of forest dynamics after accounting for the spatial structure of forest bird distribution changes. The steps followed in the hierarchical model were:
- Step 1. Because spatial processes are likely to underline changes in distribution between two time periods via ecological processes (Selmi \& Boulinier, 2001), we included four spatial variables (contagion variables) summarizing information on the species richness variation in the vicinity of a given square. With the contagion variables' approach, we are also explicitly accounting for spatial autocorrelation in the bird data.

- Step 2. Availability of habitat was assumed to be the first determining factor on bird species population in previous studies (see Moreira et al., 2001). Moreover, it was shown that forest area was the first determinant of forest bird species richness in the study area apart from other forest composition and structural features (Gil-Tena et al., 2007). Thus, in this step we considered those forest dynamics related with habitat availability such as forest spread and fire. We included the variation and the initial amount of forest area and their respective contagion variables as predictors in this model; regarding forest fires we considered the amount of forest burnt area during the 20-year period between atlases and its contagion variables.

- Step 3. After accounting for the availability of forest, forest maturation was considered, as a change of forest structure, by including in the model the forest maturation descriptors (initial basal area, its variation and their respective contagion variables).

MODEL 2. If forest bird contagion variables are not considered, forest dynamics may still explain forest bird distribution changes if these are mediated by changes in forest structure or extent at large spatial scales. This hierarchical model was similar to MODEL 1, but did not include step 1 (assessment of contagion variables).

MODEL 3. Forest maturation acting at regional scales may be the main forest dynamic influencing forest bird distribution changes as most of the considered forest bird species (see Appendix Table A1) are associated with more mature forests (Blondel \& Farré, 1988). We developed three different regression models considering separately each of the variables describing different forest dynamics, that is, change in forest area for forest spread, change in basal area for forest maturation and burnt area for fires together with their respective contagion variables.

\section{Results}

Spatial patterns of bird distribution change and forest dynamics

The observed changes in the distribution of both specialist and generalist forest birds showed a strong and 
quite uniform spatial structure indicated by the high correlation between changes occurring at a single $10 \mathrm{~km} \times 10 \mathrm{~km}$ UTM square and variations recorded in neighbouring squares at the landscape and regional extents (Fig. 2).

The processes affecting forest extent and structure during the study period showed a variety of patterns in their spatial structure (Fig. 3). Increases in forest cover and fire impact appeared to occur mainly as local or landscape processes (decreasing autocorrelation trends at greater spatial extents), especially for forest spread ( $R^{2}$ from 0.46 to 0.13 ). Regarding forest maturation, the

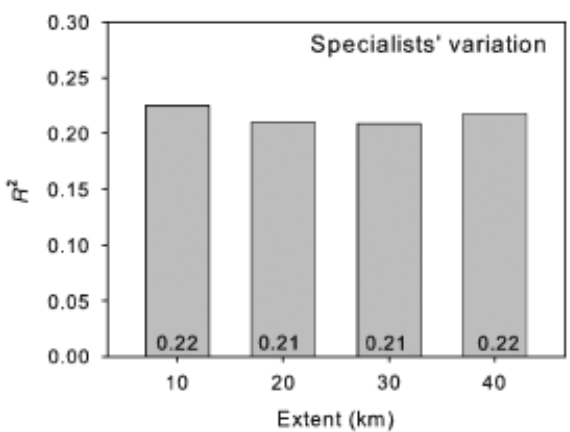

spatial pattern of forest structure change seemed to be uniform with still a strong correlation at regional scales (Fig. 3).

\section{Relationships between forest and bird change}

Changes in forest bird distribution in a given square were significantly associated to both those occurring in the neighbouring squares and also to forest dynamics at the local scale $\left(R^{2}=0.29\right.$; MODEL 1 ; Table 1$)$. Avian contagion variables explained $96 \%$ of the variability, being the contagion at the landscape scale the most

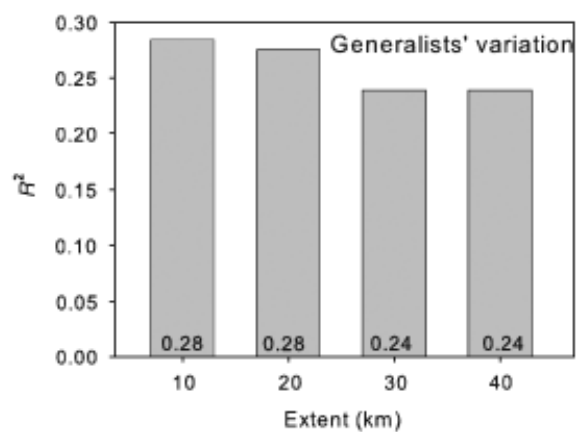

Fig. 2 Spatial patterns of bird distribution changes (species richness variation) according to the specialization group. The scales of analysis were: local at the $10 \mathrm{~km} \times 10 \mathrm{~km}$ UTM square extent, landscape for the contagion variables at the extent of 10 and $20 \mathrm{~km}$ and regional for the contagion variables at extents equal or greater than $30 \mathrm{~km}$. The models developed were significant at $P<0.0005$.
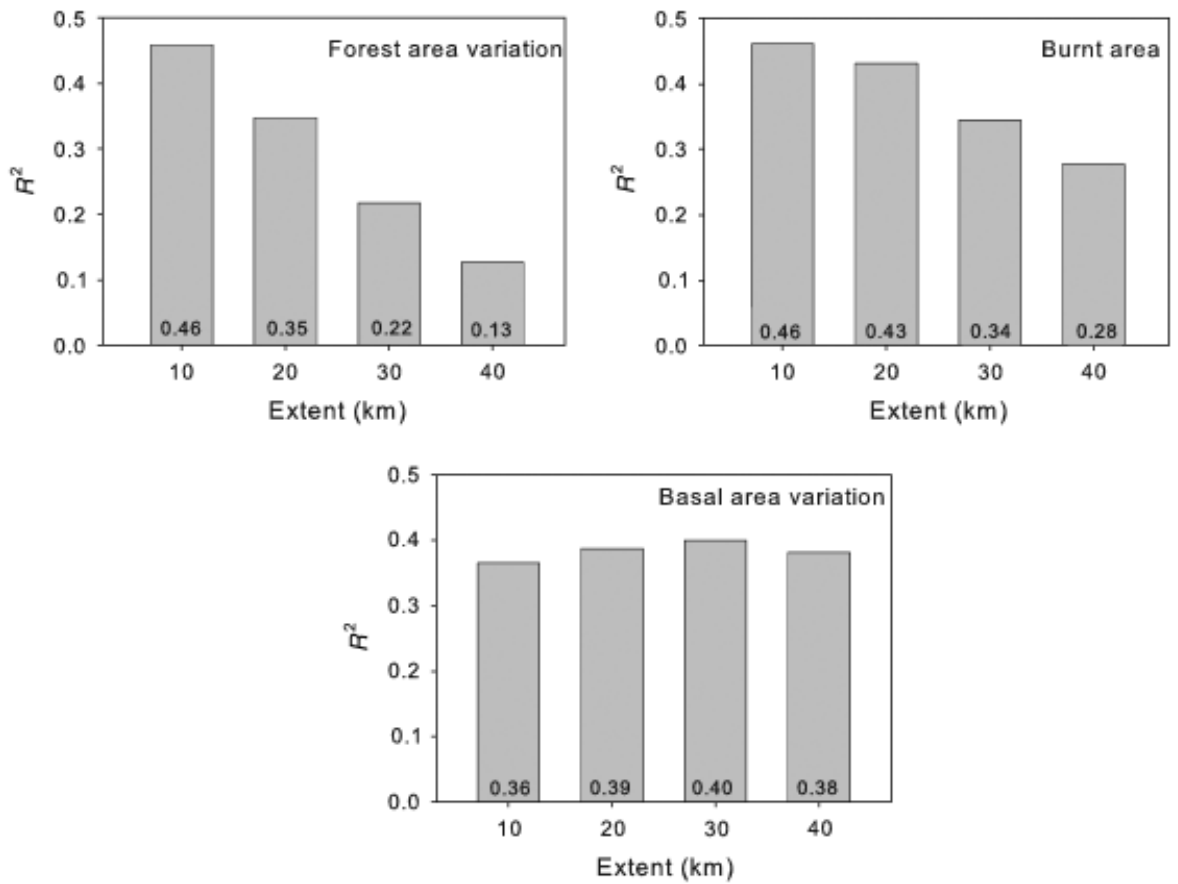

Fig. 3 Spatial patterns of forest dynamics: forest spread, maturation and fires described by forest and basal area variation and burnt area, respectively. The scales of analysis were: local at the $10 \mathrm{~km} \times 10 \mathrm{~km}$ UTM square extent, landscape for the contagion variables at the extent of 10 and $20 \mathrm{~km}$ and regional for the contagion variables at extents equal or greater than $30 \mathrm{~km}$. The models developed were significant at $P<0.0005$. 
Table 1 Analysis of the factors behind changes in species richness between the two atlas periods considering avian contagion variables and forest dynamics (corresponding to MODEL 1). The mixed models were conducted in three steps according a hierarchical process. Step 1: with avian contagions as independent variables; Step 2: with the significant variables of the former step (1) and forest spread and fire descriptors as independent variables; Step 3: with the significant variables of the former steps ( 1 and 2 ) and forest maturation descriptors as independent variables. The best model had an AIC value of 2552.8. The information in the table concerns to that of each variable in their corresponding step of assessment

\begin{tabular}{|c|c|c|c|c|}
\hline & Influence & $\begin{array}{l}\text { Type III, } \\
F\end{array}$ & $P$ & $R^{2}$ \\
\hline \multicolumn{5}{|c|}{ Step 1: Avian contagion variables } \\
\hline Variation 10 & + & 156.43 & $<0.0001$ & 0.261 \\
\hline Variation 40 & + & 20.20 & $<0.0001$ & 0.017 \\
\hline \multicolumn{5}{|c|}{$\begin{array}{l}\text { Step 2: Forest spread and fires } \\
\text { None }\end{array}$} \\
\hline \multicolumn{5}{|c|}{ Step 3: Forest maturation } \\
\hline $\begin{array}{c}\text { Basal area } \\
\text { variation }\end{array}$ & + & 10.33 & 0.0014 & 0.012 \\
\hline Model & & & & 0.290 \\
\hline
\end{tabular}

Variations 10 and 40 are the avian contagion variables at the extent of 10 and $40 \mathrm{~km}$.

influencing (Variation 10), although the regional scale (Variation 40) was also associated to forest bird distribution changes occurring at the local scale. After accounting for avian contagion variables, changes in forest bird distribution were only weakly related to forest maturation at the local scale ( $\Delta$ Basal area).

When we excluded avian contagion variables (MODEL 2; Table 2), the amount of explained variation decreased compared with the former model (a decrease in the explained variation of $28 \%$; Tables 1 and 2). In MODEL 2, variables describing forests at broader scales became important. In particular, these changes were strongly associated with the increase of forest area at the regional extent ( $\Delta$ Forest area $40 ; R^{2}=0.18$ ). In addition, there was a significant relation of forest maturation with species richness variation, not only at the regional extent ( $\triangle$ Basal area $40 ; R^{2}=0.02$ ) but also at the local scale $\left(\Delta\right.$ Basal area; $\left.R^{2}=0.01\right)$.

Finally, when considering separately the effects of forest dynamics on forest bird distribution changes (MODEL 3; Table 3), forest maturation, mainly as a regional process occurring all over the study area $(\Delta$ Basal area 40$)$, was confirmed as the best predictor of forest bird distribution changes explaining $20 \%$ of the total variability in forest birds. Nevertheless, forest spread considered as a regional process also seemed to be a major predictor of forest bird distribution changes $\left(R^{2}=0.18\right)$. As in the former models, forest
Table 2 Analysis of the factors behind changes in species richness between the two atlas periods considering only forest dynamics (corresponding to MODEL 2). The mixed models were conducted in two steps according a hierarchical process. Step 1: with forest spread and fire descriptors as independent variables; Step 2: with the significant variables in the former step (1) and forest maturation descriptors as independent variables. The best model had an AIC value of 2628.3. The information in the table concerns to that of each variable in their corresponding step of assessment

\begin{tabular}{llrrr}
\hline \multicolumn{5}{c}{ Type III, } \\
& Influence & $F$ & \multicolumn{1}{c}{$P$} & \multicolumn{1}{c}{$R^{2}$} \\
\hline Step 1: Forest spread and fires & & & \\
$\quad$ Forest area variation $40+$ & 69.28 & $<0.0001$ & 0.177 \\
Step 2: Forest maturation & & & & \\
$\quad$ Basal area variation 40 & + & 59.64 & $<0.0001$ & 0.021 \\
$\quad$ Basal area variation & + & 9.03 & 0.0028 & 0.012 \\
Model & & & & 0.210 \\
\hline
\end{tabular}

Forest area variation 40 and basal area variation 40 are the contagion variables for forest and basal area variation, respectively, at the extent of $40 \mathrm{~km}$.

Table 3 Analysis of the factors behind changes in species richness between the two atlas periods considering each forest dynamic individually and including the absolute variation and their respective contagion variables (corresponding to MODEL 3). The best model had an AIC value of 2652.2 for forest spread and 2628.1 for forest maturation

\begin{tabular}{|c|c|c|c|c|}
\hline & Influence & $\begin{array}{l}\text { Type III, } \\
F\end{array}$ & $P$ & $R^{2}$ \\
\hline \multicolumn{5}{|l|}{ Forest spread } \\
\hline$\Delta$ Forest area 40 & + & 69.28 & $<0.0001$ & 0.177 \\
\hline Model & & & & 0.177 \\
\hline \multicolumn{5}{|l|}{ Forest maturation } \\
\hline$\Delta$ Basal area 40 & + & 139.38 & $<0.0001$ & 0.184 \\
\hline$\Delta$ Basal area & + & 9.50 & 0.0021 & 0.013 \\
\hline Model & & & & 0.197 \\
\hline
\end{tabular}

Forest area variation 40 and basal area variation 40 are the contagion variables for forest and basal area variation, respectively, at the extent of $40 \mathrm{~km}$.

fires did not appear to affect forest bird changes. For all the models carried out, there was a lack of significance of the specialization group and an absence of significant interactions (Tables 1-3).

\section{Discussion}

As shown by our results, forest dynamics mainly associated with land abandonment as forest maturation and forest spread have played a fundamental role in shaping forest bird changes in Catalonia during the last 20 
years. Both forest dynamics influenced changes in forest birds mainly at the regional scale, although forest spread was identified as being more a local or landscape process (Fig. 3). There were no significant differences in distribution changes between specialists and generalists and, thus, forest dynamics appeared to equally affect both ecological groups.

Forest maturation was revealed as the most influencing dynamic in line with the view that most of the forest bird species in the Mediterranean, such as elsewhere in Europe, are more related with advanced forest development stages than with initial successional stages as those typical of young (recently colonized) forests (Blondel \& Farré, 1988; Suárez-Seoane et al., 2002). Usually, more forest bird species are associated with older age classes, which may be linked with a more developed and complex forest vertical structure (Herrando \& Brotons, 2002; Venier \& Pearce, 2005), where forest species may find more and varied resources. Besides, maturation is especially important in the Mediterranean where old-growth forests are scarce due to long-lasting human interference. The average stand age of Catalan forests is under 50 years for most of the forest types (Gracia et al., 2004). Despite the prevalent role of forest maturation in forest bird distribution changes shown in the present study, previous studies have not explicitly considered the effect of forest maturation and focused on forest spread (e.g. Reif et al., 2007).

Although new forests may not apparently fulfil the habitat requirements for those forest bird species more linked to advanced development stages, the general forest spread occurring in Catalonia, acting mainly as a local or landscape process, seemed to have favoured the expansion of this group of birds. New forests in former agricultural lands may be indicating their new role as sink or supplementary habitats for forest birds (Bowen et al., 2007). Besides, new available forest habitats may be beneficial for some pioneer species, but the landscape homogenization produced by the spread of forest may also be a threat for those forest bird species which need mosaics or more open habitats (see Sirami et al., 2007b). Therefore, and on a species idiosyncratic manner, it may be necessary to manage new forested habitats to maintain heterogeneous landscapes.

Thus, forest bird species in the Mediterranean appear to be favoured by both forest maturation and spread. This contrasts with the situation in other parts of Europe as Britain, where most forest birds may be declining due to several factors such as the lack of management and subsequent loss of young forests and other specific problems at local scales as the effect of deer grazing (Fuller et al., 2005).

Another possible pointed factor causing forest bird declines may be climate change (Archaux, 2003; Fuller et al., 2005; Leech \& Crick, 2007); nevertheless, in the French Alps, Archaux (2004) showed that most of the forest bird species here considered did not seem to manifest a negative response to climate change, despite the significant warming produced in the zone during the last decades. In the Mediterranean region, land-use change may be the main cause of recent changes in bird populations (Sirami et al., 2007a; Seoane \& Carrascal, 2008), which agrees with the positive influence of forest maturation and spread on forest bird changes. Besides, recently Bowen et al. (2007) pointed out that regrowth forests may play an important role in buffering against the adverse effects of climate change by improving population or metapopulation persistence through increasing habitat area and enhanced landscape connectivity.

Despite the fact that fires are a prominent factor impacting landscapes across the entire Mediterranean basin, we did not find a negative influence on forest bird distribution changes at the scales analysed here. Nevertheless, we cannot claim that at finer scales $(<10 \mathrm{~km} \times 10 \mathrm{~km})$, forest fires did not have a negative effect on this group. It is worth noting, however, that fire-related landscapes seem to have a low impact on forest bird species in the Mediterranean basin. Herrando \& Brotons (2002) showed that the mosaic-like landscapes shaped by fires in the Mediterranean basin are not strongly associated with negative fragmentation effects on forest birds other than those related with habitat loss. In addition, forest fragments within Mediterranean mosaics created by wildfires allow some forest bird species to respond positively to the disruption because habitat heterogeneity at a local scale appears a key factor in maintaining bird diversity in fire-driven Mediterranean landscapes (Brotons et al., 2004). As suggested by Moreira \& Russo (2007), in the Mediterranean, wildfire impacts will not necessarily be always negative for vertebrates at certain scales depending on the fire regime.

The absence of differences between specialization groups on forest bird changes agrees with the weak relation showed between habitat breadth and bird population trends in Spain (Seoane \& Carrascal, 2008), although Julliard et al. (2004) found that habitat specialization is related to bird-declining rates in France. This lack of differences between specialists and generalists may be related to the fact that the Mediterranean region lacks true forest specialists and most species of both groups may be considered relatively generalists from a European perspective (Covas \& Blondel, 1998), thus leading to minor differences in overall responses to changes in forest structure.

According to our results, forest bird distribution changes were strongly related to spatial population 

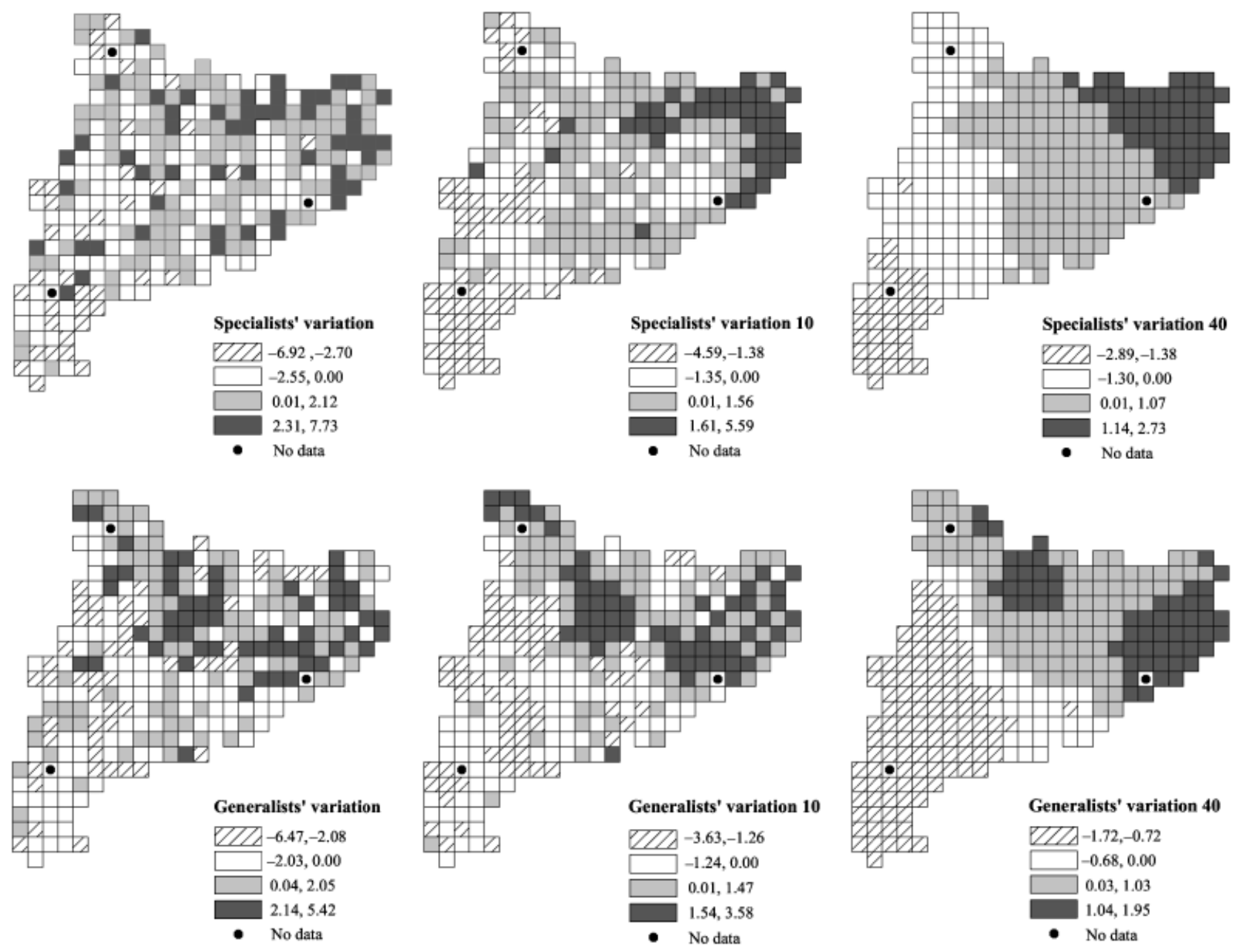

Fig. 4 Patterns of distribution in Catalonia of the species richness variation after considering sampling effort and of their significant contagion variables in the mixed models according to their specialization degree. Specialists' variations 10 and 40 , and Generalists' variations 10 and 40 are the avian contagion variables after considering sampling effort at the extent of 10 and $40 \mathrm{~km}$ for each specialization group.

processes occurring not only at the local level but also at neighbouring locations as shown previously (Brotons et al., 2005, 2008; Gimona \& Brewer, 2006). Besides, there was also an influence of forest dynamics occurring at multiple scales on forest birds (Fig. 2). Processes occurring at regional scales were the main drivers of forest bird distribution changes, although once accounted for regional processes the local scale took relevance. Thus, a multiscale analysis is needed to evaluate the influence of land changes due to global change on bird distribution variations as done previously (Sirami et al., 2007b). Moreover, spatial population processes followed similar distributional patterns at regional scales with forest dynamics by means of a south-to-north gradient of increasing values across the study region (Figs 4 and 5). This gradient may explain why forest dynamics at greater extents gained importance when avian contagion variables were not considered, reflecting common underlying biogeographical patterns associated to them as climate. In general, the unexplained variation of the models may evidence that other large-scale factors not considered here affected forest bird distribution changes or maybe other processes acting at finer scales than $10 \mathrm{~km} \times 10 \mathrm{~km}$. For instance, at local scales the role of forest management in forest bird distribution changes should be considered. Mediterranean forest ecosystems have been managed for centuries and forest management might affect the availability and quality of forest habitats, which would influence on bird distribution and also on the severity of forest fires by modifying horizontal and vertical fuel continuity. In addition, further research is needed to evaluate the herein considered forest dynamics in future scenarios where climate warming and fire increase are expected to have a large impact in the Mediterranean forests in next decades (see Colombaroli et al., 2007). 

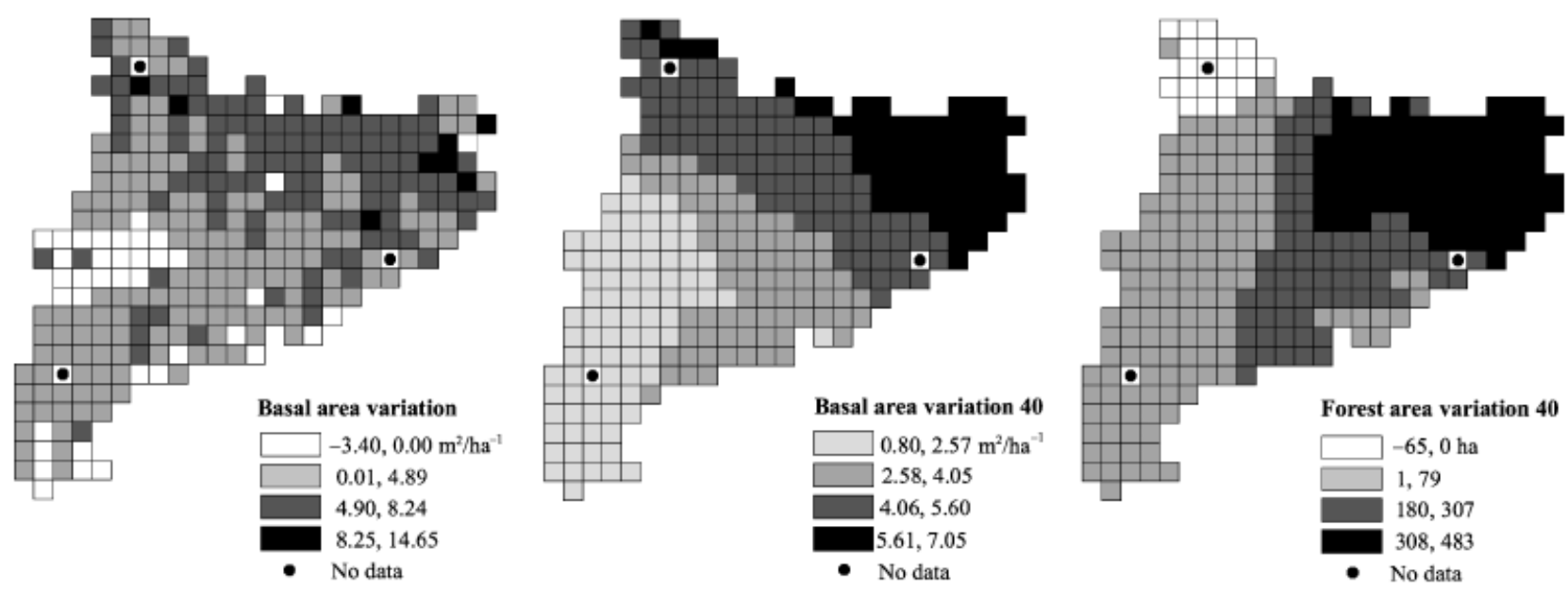

Fig. 5 Patterns of distribution in Catalonia of the significant variables in the mixed models concerning forest dynamics. Basal area variation 40 and forest area variation 40 are the contagion variables at the extent of $40 \mathrm{~km}$ for basal and forest area variation, respectively.

\section{Acknowledgements}

We want to thank and recognize the careful and collaborative task of all the contributors of the CBBA and all the ICO volunteers. We thank Xavier Averós Florensa and M. Àngels Colomer Cugat from the University of Lleida for their advice in data analysis. This work has received financial support from the MEC (Spain) and FEDER funds through the IBEPFOR (CGL200600312/BOS) and DINDIS (CGL2005-00031/BOS) projects and is a contribution to the European Research Group GDRE 'Mediterranean and mountain systems in a changing world'. The NFI data was supplied by the DGB (MIMAM, Spain). We also like to thank Asier Larrañaga and Edgar Nebot from the GRAF brigade and Josep Llaquet (Catalan government) for the fire data. A. GilTena benefited from a predoctoral grant (2008FIC-00195) with the support of the CUR of the DIUE and the European Social Fund, and L. Brotons from a Ramon y Cajal contract (Spanish government).

\section{References}

Archaux F (2003) Birds and climate change. Vie et Milieu, 53, 3341.

Archaux F (2004) Breeding upwards when climate is becoming warmer: no bird response in the French Alps. Ibis, 146, 138144.

Augustin NH, Mugglestone MA, Buckland ST (1996) An autologistic model for the spatial distribution of wildlife. Journal of Applied Ecology, 33, 339-347.

Blondel J (2006) The 'design' of Mediterranean landscapes: a millennial story of humans and ecological systems during the historic period. Human Ecology, 34, 713-729.

Blondel J, Farré H (1988) The convergent trajectories of bird communities along ecological successions in European forests. Oecologia, 75, 83-93.

Boisvenue C, Running SW (2006) Impacts of climate change on natural forest productivity - evidence since the middle of the 20th century. Global Change Biology, 12, 862-882.
Bowen ME, McAlpine CA, House APN, Smith GC (2007) Regrowth forests on abandoned agricultural land: a review of their habitat values for recovering forest fauna. Biological Conservation, 140, 273-296.

Brotons L, Herrando S, Martin JL (2004) Bird assemblages in forest fragments within Mediterranean mosaics created by wild fires. Landscape Ecology, 19, 663-675.

Brotons L, Herrando S, Pons P (2008) Wild fires and the expansion of threatened farmland birds: the Ortolan bunting (Emberiza hortulana) in Mediterranean landscapes. Journal of Applied Ecology, 45, 1059-1066.

Brotons L, Pons P, Herrando S (2005) Colonization of dynamic Mediterranean landscapes: where do birds come from after fire? Journal of Biogeography, 32, 789-798.

Carnicer J, Brotons L, Sol D, De Cáceres M (2008) Random sampling, abundance-extinction dynamics and niche-filtering immigration constraints explain the generation of species richness gradients. Global Ecology and Biogeography, 17, 352362.

Catalan Department of Housing and Environment Prevenció d'incendis forestals- Medi Ambient i Habitatge (2007), http://mediambient.gencat.net/cat/el_medi/incendis/.

Colombaroli D, Marchetto A, Tinner W (2007) Long-term interactions between Mediterranean climate, vegetation and fire regime at Lago di Massaciuccoli (Tuscany, Italy). Journal of Ecology, 95, 755-770.

Covas R, Blondel J (1998) Biogeography and history of the Mediterranean bird fauna. Ibis, 140, 395-407.

Debussche M, Lepart J, Dervieux A (1999) Mediterranean landscape changes: evidence from old postcards. Global Ecology and Biogeography, 8, 3-15.

Díaz-Delgado R, Lloret F, Pons X (2004) Spatial patterns of fire occurrence in Catalonia, NE, Spain. Landscape Ecology, 19, 731-745.

Diniz-Filho JAF, Bini LM, Hawkins BA (2003) Spatial autocorrelation and red herrings in geographical ecology. Global Ecology and Biogeography, 12, 53-64.

Donald PF, Fuller RJ (1998) Ornithological atlas data: a review of uses and limitations. Bird Study, 45, 129-145. 
Estrada J, Pedrocchi V, Brotons L, Herrando S (2004) Atles dels ocells nidificants de Catalunya 1999-2002. Institut Català d'Ornitologia (ICO)/Lynx Edicions, Barcelona.

Fuller RJ, Noble DG, Smith KW, Vanhinsbergh D (2005) Recent declines in populations of woodland birds in Britain: a review of possible causes. British Birds, 98, 116-143.

Gil-Tena A, Saura S, Brotons L (2007) Effects of forest composition and structure on bird species richness in a Mediterranean context: implications for forest ecosystem management. Forest Ecology and Management, 242, 470-476.

Gimona A, Brewer MJ (2006) Local environmental effects and spatial effects in macroecological studies using mapped abundance classes: the case of the rook Corvus frugilegus in Scotland. Journal of Animal Ecology, 75, 1140-1146.

Gracia C, Burriel JA, Ibàñez JJ, Mata T, Vayreda J (2000-2004) Inventari ecològic i forestal de Catalunya. Obra completa. CREAF, Bellaterra, Barcelona.

Gregory R, Vorisek P, Van Strien A et al. (2007) Population trends of widespread woodland birds in Europe. Ibis, 149, 78-97.

Herrando S, Brotons L (2002) Forest bird diversity in Mediterranean areas affected by wildfires: a multi-scale approach. Ecography, 25, 161-172.

IGBP (2001) Global change and the Earth system: a planet under pressure. IGBP Science Series, 4, $41 \mathrm{pp}$.

Julliard R, Jiguet F, Couvet D (2004) Common birds facing global changes: what makes a species at risk? Global Change Biology, 10, 148-154.

Laiolo P (2005) Spatial and seasonal patterns of bird communities in Italian agroecosystems. Conservation Biology, 19, 1547-1556.

Lavorel S, Canadell J, Rambal S, Terradas J (1998) Mediterranean terrestrial ecosystems: research priorities on global change effects. Global Ecology and Biogeography Letters, 7, 157-166.

Leech DI, Crick HQP (2007) Influence of climate change on the abundance, distribution and phenology of woodland bird species in temperate regions. Ibis, 149, 128-145.

Lloret F, Calvo E, Pons X, Díaz-Delgado R (2002) Wildfires and landscape patterns in the Eastern Iberian peninsula. Landscape Ecology, 17, 745-759.

Ministerio de Medio de Medio Ambiente (2006) Tercer Inventario Forestal Nacional. Lleida. Dirección General de Conservación de la Naturaleza, Madrid.

Moreira F, Ferreira PG, Rego FC, Bunting S (2001) Landscape changes and breeding bird assemblages in northwestern Portugal: the role of fire. Landscape Ecology, 16, 175-187.

Moreira F, Russo D (2007) Modelling the impact of agricultural abandonment and wildfires on vertebrate diversity in Mediterranean Europe. Landscape Ecology, 22, 1461-1476.

Mouillot F, Field CB (2005) Fire history and the global carbon budget: a 1 degrees $\times 1$ degrees fire history reconstruction for the 20th century. Global Change Biology, 11, 398-420.

Mouillot F, Ratte JP, Joffre R, Mouillot D, Rambal S (2005) Longterm forest dynamic after land abandonment in a fire prone Mediterranean landscape (central Corsica, France). Landscape Ecology, 20, 101-112.

Peñuelas J, Filella I, Comas P (2002) Changed plant and animal life cycles from 1952 to 2000 in the Mediterranean region. Global Change Biology, 8, 531-544.
Piñol J, Terradas J, Lloret F (1998) Climate warming, wildfire hazard, and wildfire occurrence in coastal eastern Spain. Climatic Change, 38, 345-357.

Poyatos R, Latron J, Llorens P (2003) Land use and land cover change after agricultural abandonment - the case of a Mediterranean mountain area (Catalan Pre-Pyrenees). Mountain Research and Development, 23, 362-368.

Preiss E, Martin JL, Debussche M (1997) Rural depopulation and recent landscape changes in a Mediterranean region: consequences to the breeding avifauna. Landscape Ecology, 12, 51-61.

Reif J, Vořrišek P, Št́astny̆ K, Bejček V, Petr J (2007) Population increase of forest birds in the Czech Republic between 1982 and 2003. Bird Study, 54, 248-255.

Roura-Pascual N, Pons P, Etienne M, Lambert B (2005) Transformation of a rural landscape in the Eastern Pyrenees between 1953 and 2000. Mountain Research and Development, 25, 252-261.

Sala OE, Chapin III FS, Armesto JJ et al. (2000) Global biodiversity scenarios for the year 2100. Science, 287, 1770-1774.

Selmi S, Boulinier T (2001) Ecological biogeography of Southern Ocean islands: the importance of considering spatial issues. American Naturalist, 158, 426-437.

Seoane J, Carrascal LM (2008) Interspecific differences in population trends of Spanish birds are related to habitat and climatic preferences. Global Ecology and Biogeography, 17, 111121.

Sirami C, Brotons L, Burfield I, Fonderflick J, Martin JL (2007a) Is land abandonment having an impact on biodiversity? A meta-analytical approach to bird distribution changes in the north-western Mediterranean. Biological Conservation, 141, 450-459.

Sirami C, Brotons L, Martin JL (2007b) Vegetation and songbird response to land abandonment: from landscape to census plot. Diversity and Distributions, 13, 42-52.

Suárez-Seoane S, Osborne PE, Baudry J (2002) Responses of birds of different biogeographic origins and habitat requirements to agricultural land abandonment in northern Spain. Biological Conservation, 105, 333-344.

Terradas J, Gracia C, Àvila A, Ibàñez JJ, Espelta JM, Vayreda J (2004) Els boscos de Catalunya. Estructura, dinàmica i funcionament. Documents dels Quaderns de Medi Ambient, 11. Departament de Medi Ambient i Habitatge, Generalitat de Catalunya, Barcelona.

Thomas CD, Cameron A, Green RE et al. (2004) Extinction risk from climate change. Nature, 427, 145-148.

Vega-García C, Chuvieco E (2006) Applying local measures of spatial heterogeneity to Landsat-TM images for predicting wildfire occurrence in Mediterranean landscapes. Landscape Ecology, 21, 595-605.

Venier LA, Pearce JL (2005) Boreal bird community response to jack pine forest succession. Forest Ecology and Management, 217, 19-36.

Viñas O, Baulies X (1995) 1:250,000 land-use map of Catalonia $\left(32,000 \mathrm{~km}^{2}\right)$ using multi-temporal Landsat-TM data. International Journal of Remote Sensing, 16, 129-146. 


\section{Appendix A}

Table A1 Forest bird species considered, classified depending on their degree of specialization (class) in specialists (S) or generalists $(\mathrm{G})$

\begin{tabular}{|c|c|c|c|}
\hline Forest bird species & $N$ & Trend* & Class \\
\hline Accipiter gentilis & 195 & -18 & $S$ \\
\hline Aegithalos caudatus & 333 & ns & $S$ \\
\hline Anthus trivialis & 87 & ns & G \\
\hline Caprimulgus europaeus & 278 & +32 & G \\
\hline Circaetus gallicus & 298 & +56 & G \\
\hline Corvus corax & 295 & ns & G \\
\hline Corvus corone & 256 & ns & G \\
\hline Dendrocopos major & 274 & +48 & $S$ \\
\hline Dendrocopos minor & 42 & +631 & $S$ \\
\hline Dryocopus martius & 86 & +109 & $S$ \\
\hline Erithacus rubecula & 317 & +7 & $S$ \\
\hline Falco subbuteo & 177 & +35 & G \\
\hline Fringilla coelebs & 304 & ns & $S$ \\
\hline Hieraaetus pennatus & 97 & +1638 & G \\
\hline Lullula arborea & 299 & +20 & G \\
\hline Otus scops & 293 & -13 & G \\
\hline Parus ater & 261 & +7 & $S$ \\
\hline Parus caeruleus & 331 & -3 & S \\
\hline Parus cristatus & 314 & +8 & $S$ \\
\hline Parus palustris & 54 & ns & $S$ \\
\hline Phylloscopus collybita & 239 & +60 & $S$ \\
\hline Picus viridis & 346 & -2 & G \\
\hline Regulus ignicapilla & 295 & +8 & $\mathrm{~S}$ \\
\hline Sitta europaea & 158 & +13 & $S$ \\
\hline Strix aluco & 279 & ns & G \\
\hline Sylvia atricapilla & 335 & +6 & $S$ \\
\hline Sylvia cantillans & 256 & +31 & G \\
\hline Troglodytes troglodytes & 325 & -3 & G \\
\hline Turdus philomelos & 260 & +22 & $S$ \\
\hline Turdus viscivorus & 327 & -4 & G \\
\hline
\end{tabular}

*Trend considering sampling effort (\% change).

$N$ is the number of $10 \mathrm{~km} \times 10 \mathrm{~km}$ UTM squares where a species was counted in the Atlas 2 (from a total of $38510 \mathrm{~km} \times 10 \mathrm{~km}$ UTM squares surveyed). 